\title{
Temporal trend of green space coverage in China and its relationship with urbanization over the last two decades
}

\author{
Juanjuan Zhao ${ }^{\text {a,b,*, }}$, Shengbin Chen ${ }^{\mathrm{c}, 1}$, Bo Jiang ${ }^{\mathrm{d}, 2}$, Yin Ren ${ }^{\mathrm{a}, \mathrm{b}, * *, 3}$, Hua Wang ${ }^{\mathrm{e}, 4}$, \\ Jonathan Vause ${ }^{\mathrm{a}, \mathrm{b}, 3}$, Haidong $\mathrm{Yu}^{\mathrm{f}, 5}$ \\ a Key Lab of Urban Environment and Health, Institute of Urban Environment, Chinese Academy of Sciences, 1799 Jimei Road, Xiamen 361021, China \\ b Xiamen Key Lab of Urban Metabolism, 1799 Jimei Road, Xiamen 361021, China \\ ${ }^{c}$ Nanjing Institute of Environmental Sciences, Ministry of Environmental Protection, 8 Jiangwangmiao Street, Nanjing 210042, China \\ d State Key Laboratory of Urban and Regional Ecology, Research Center for Eco-Environmental Sciences, Chinese Academy of Sciences, P.O. Box 2871, Beijing 100085, China \\ e Institute of Forestry and Pomology, Beijing Academy of Agriculture and Forestry Sciences, Ruiwangfen Jia 12 Xiangshan, Beijing 100093, China \\ ${ }^{\mathrm{f}}$ Xiamen Huaxia Vocational College, Wenjiaoqu Jimei District, Xiamen 361024, China
}

\section{H I G H L I G H T S}

- The green space coverage in Chinese cities increased steadily from 1991 to 2009.

- Cities in the same region exhibited long-term similar trends of development.

- Population, land area and GDP significantly affected green space coverage.

- Per capita GDP had the highest independent contribution to green space coverage.

- A linear model to predict variance in green space was constructed.

\section{A R T I C L E I N F O}

\section{Article history:}

Received 1 April 2012

Received in revised form 27 August 2012

Accepted 2 October 2012

Available online 24 November 2012

\section{Keywords:}

Urban ecology

Urban sprawl

Urban greening

Regional difference

Urbanization in China

Green space coverage

\begin{abstract}
A B S T R A C T
Irrespective of which side is taken in the densification-sprawl debate, insights into the relationship between urban green space coverage and urbanization have been recognized as essential for guiding sustainable urban development. However, knowledge of the relationships between socio-economic variables of urbanization and long-term green space change is still limited. In this paper, using simple regression, hierarchical partitioning and multi-regression, the temporal trend in green space coverage and its relationship with urbanization were investigated using data from 286 cities between 1989 and 2009, covering all provinces in mainland China with the exception of Tibet. We found that: [1] average green space coverage of cities investigated increased steadily from $17.0 \%$ in 1989 to $37.3 \%$ in 2009; [2] cities with higher recent green space coverage also had relatively higher green space coverage historically; [3] cities in the same region exhibited similar long-term trends in green space coverage; [4] eight of the nine variables characterizing urbanization showed a significant positive linear relationship with green space coverage, with 'per capita GDP' having the highest independent contribution (24.2\%); [5] among the climatic and geographic factors investigated, only mean elevation showed a significant effect; and [6] using the seven largest contributing individual factors, a linear model to predict variance in green space coverage was constructed. Here, we demonstrated that green space coverage in built-up areas tended to reflect the effects of urbanization rather than those of climatic or geographic factors. Quantification of the urbanization effects and the characteristics of green space development in China may provide a valuable reference for research into the processes of urban sprawl and its relationship with green space change.
\end{abstract}

(c) 2012 Elsevier B.V. All rights reserved.

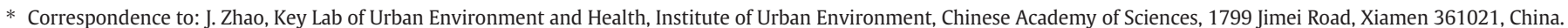
Tel.: + 86592 6190691; fax: + 865926190977.

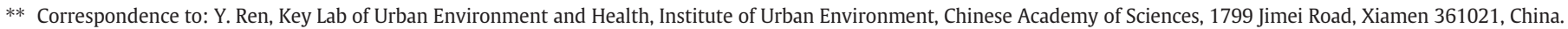
Tel.: + 86592 6190679; fax: +865926190977.

E-mail addresses: jjzhao@iue.ac.cn (J. Zhao), chainpin@yahoo.com.cn (S. Chen), jbshuibao415@126.com (B. Jiang), yren@iue.ac.cn (Y. Ren), wanghuaphd@gmail.com (H. Wang), jonathanvause@hotmail.com (J. Vause), hoste@163.com (H. Yu).

1 Tel.: + 86 18752028663; fax: +862585411611.

2 Tel.: + 86 18618349748; fax: + 861062943822 .

3 Tel.: + 86 13666063590; fax: + 865926190977

${ }^{4}$ Tel.: + 86 15810159776; fax: + 861062598744 .

5 Tel.: + 86 13400665256; fax: + 865926276246 .
} 


\section{Introduction}

Urban green spaces can be defined as outdoor places with significant amounts of vegetation, which exist mainly as semi-natural areas (Jim and Chen, 2003). As cities continue to sprawl and urban populations continue to grow, the remaining nature within cities becomes disproportionately important (Crane and Kinzig, 2005). Typically, urban green spaces have important ecological effects, contribute to public health, and increase the life quality of urban citizens by offering esthetic enjoyment, recreational opportunities and improvements in physical and psychological well-being (Jo, 2002; Chen and Jim, 2008). Recent reports also found that carbon density in urban areas $\left(23-42 \mathrm{~kg} \mathrm{C} \mathrm{m}^{-2}\right.$ in sample cities of the United States, Churkina et al., 2010; $3.16 \mathrm{~kg} \mathrm{C}$ $\mathrm{m}^{-2}$ in Leicester, UK, Davies et al., 2011) is comparable to that of some natural forests, and the dynamics of urban vegetation may leave footprints in global biogeochemical cycles (Grimm et al., 2008). The enhancement of green areas has the potential to mitigate the adverse effects of urbanization in a sustainable way (Ridder et al., 2004).

Especially in view of the recent phenomenon of urban sprawl in China, insights into the relationship between urban green space coverage and urbanization are recognized as essential for guiding sustainable urban development (Liu et al., 2011; Zhou and Wang, 2011). In response to the fast-developing urban expansion, two opposing arguments have emerged: whether cities should be allowed to 'sprawl' into the wider countryside, or 'densify' through the development of existing urban green space (Dallimer et al., 2011). By 'sprawl' into the wider countryside, it is feared that the urban sprawl leads to settlement patterns which are environmentally inefficient and have negative impacts on the surrounding countryside (e.g. Antrop, 2000; Swenson and Franklin,
2000). However, to 'densify' through the development of existing urban green space may lead to the loss of green space within the cities. This loss of quality green space, as an important reason why people move out of inner cities to the suburb may ultimately cause urban sprawl (see Beer et al., 2003). Either way, whether cities expand through sprawl or densification, quality green space is vital for the sustainable development of cities.

Actually, changes in green space have been found to be related to urbanization processes. Rapid urbanization has been reported to cause many environmental impacts associated with the reduction of green space (Ren et al., 2011; Zhou and Wang, 2011). As a process marked by urban area expansion, intensive land use change, economic development, and rapid population growth (Antrop, 2000; Weber and Puissant, 2003), urbanization exerts a profound influence on vegetation cover and productivity (Fang et al., 2003). In the case of Europe, the proportion of green space increased with city area, while mildly declining with population density (Fuller and Gaston, 2009). Infill development during which gardens were built over was found to be a major cause of green space loss (Pauleit et al., 2005). Moreover, the effects of urbanization on green space may become increasingly intensive. For example, Kirkpatrick et al. (2011) found that the links between socioeconomic conditions and urban tree cover intensified over time.

In contrast to the situation reported by the above studies, green space coverage may increase with urbanization intensity. Green space coverage in Chinese cities, for example, increased considerably between 1995 and 2009. During the last 15 years, the total area of green space in Chinese cities has increased from 0.6 million hectares to 19.9 million hectares, and the average green space coverage increased from $21.8 \%$ to $38.2 \%$ (National Bureau of Statistics of China, 1990-2010). A possible

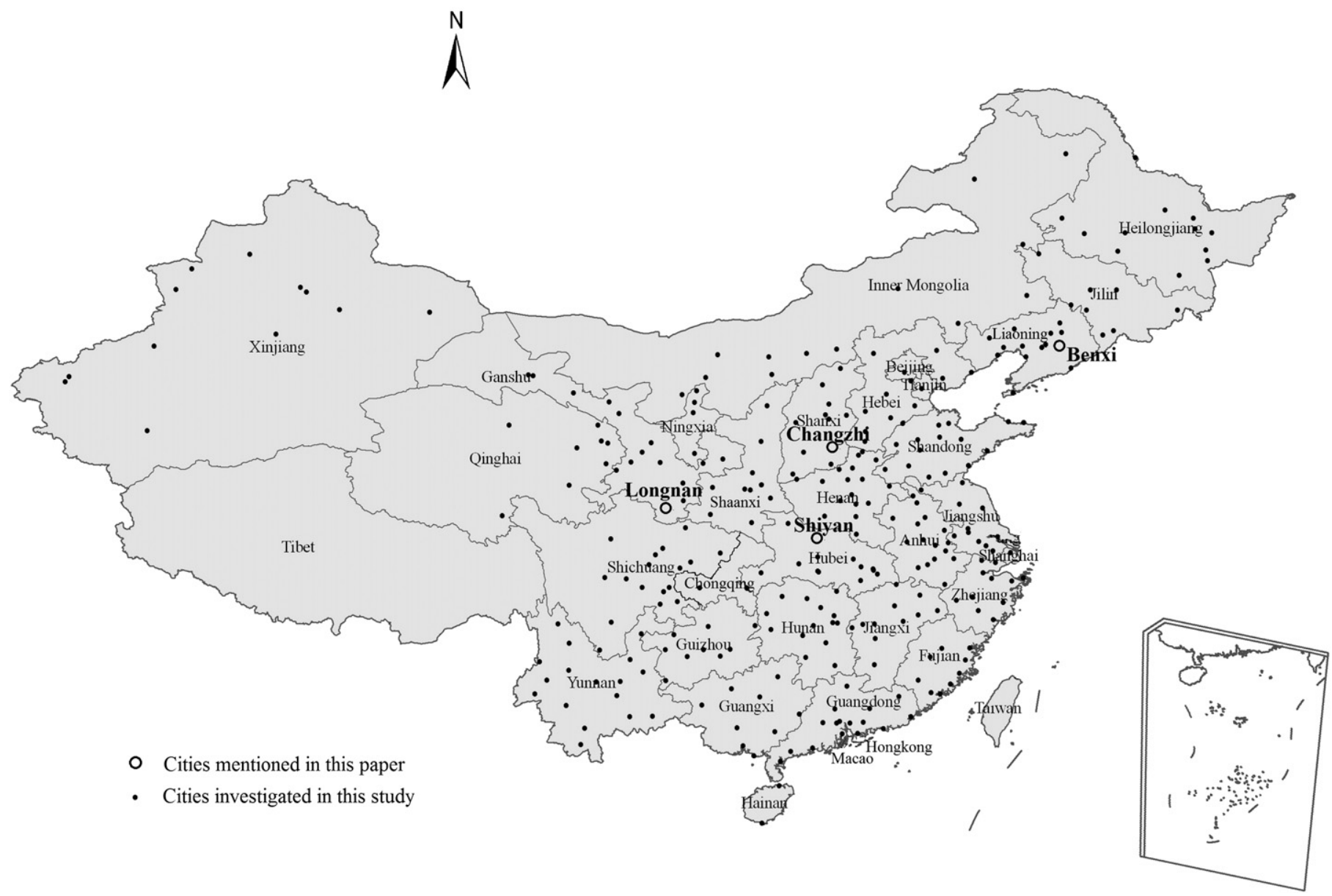

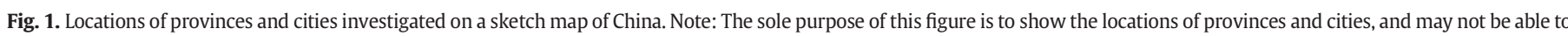
show the exact international boundaries. Representations of China's international boundaries can be controversial due to the existence of political issues and/or border disputes. 
explanation for this may be the decades of investment in green space construction and development combined with supporting planning and policies. Since 1953, the Chinese government has adopted systematic planning (Wang, 1992) and a series of policies to introduce green elements into urban areas (Zhou and Wang, 2011). Especially in the last two decades, many governmental regulations related to urban greening have been introduced. However, despite increasing interest of scientists and policymakers in the subject, our knowledge of the relationship between urbanization and green space coverage is still very limited. This is primarily due to the lack of multiyear, national scale observational data (Sun et al., 2011), which is especially limited in cases when green space actually increases with urbanization.

In this research, we hypothesized that green space quantity in cities is affected by interrelated urbanization factors which characterize the urbanization process, and take China, which is a country experiencing rapid urbanization, as a case study. 286 cities, covering all provinces in mainland China with the exception of Tibet, were analyzed to investigate the relationships between the quantity of urban green space and nine selected urbanization factors related to population, land area and economic level during the last two decades. The relationship with annual average temperature, annual precipitation and mean elevation was also investigated. Green space coverage was chosen to assess the development of green space quantity, because it is an index recorded in China's early statistical yearbooks and is also one of the most important measures in urban green space planning, management and research (Fang, 2008; Zhou and Wang, 2011). Specifically, we posted the following research questions: [1] How did green space coverage in built-up areas develop over the last two decades? [2] Was green space coverage in built-up areas more related to urbanization factors or climatic and geographic factors? [3] How did the significantly contributing factors influence green space coverage?

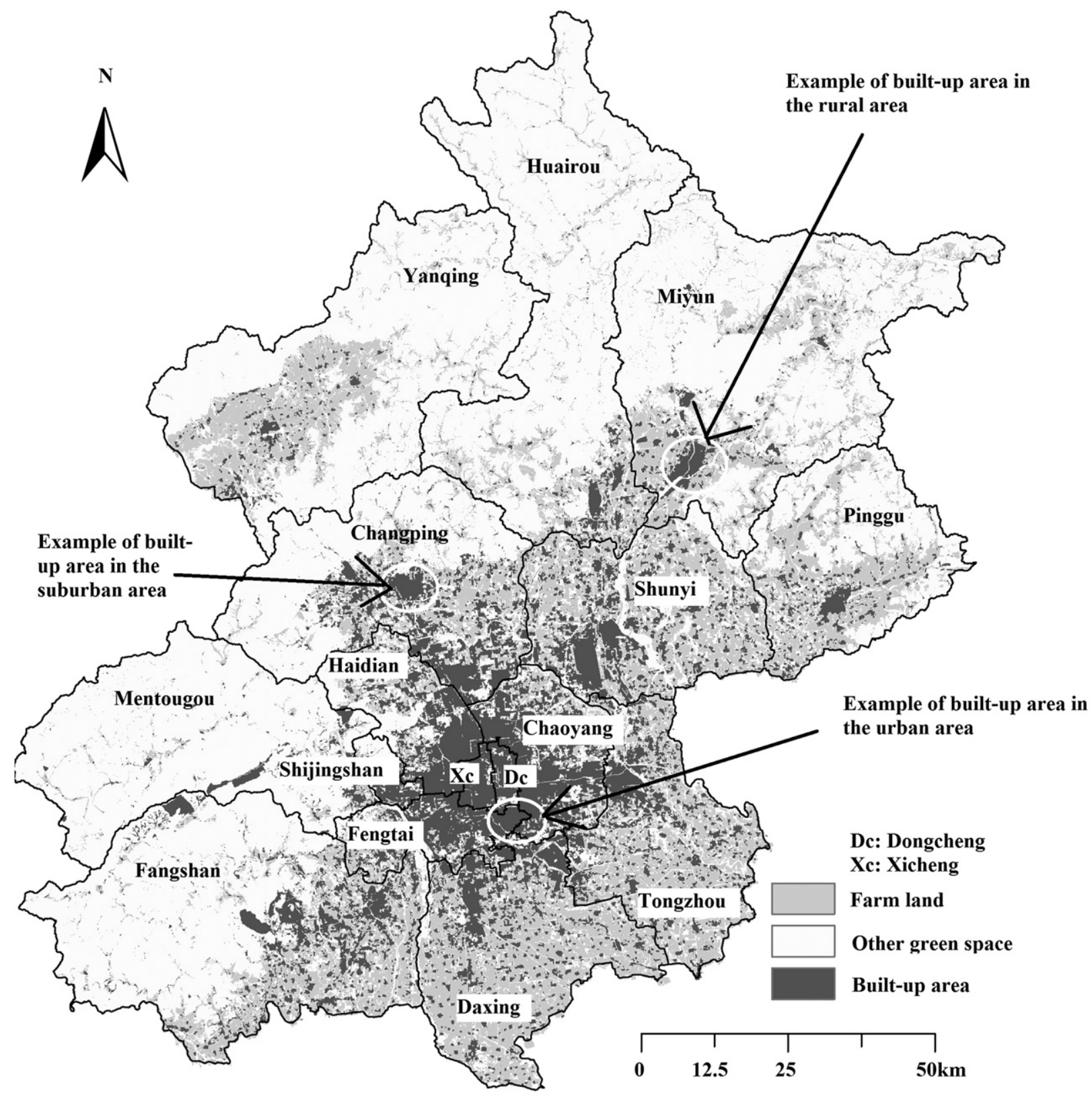

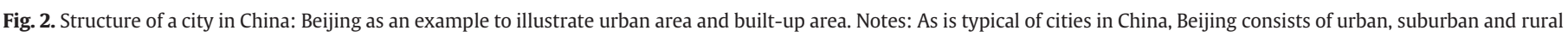

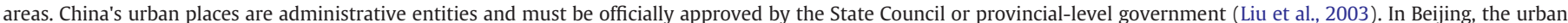

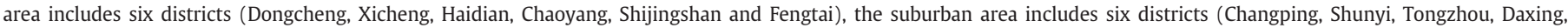

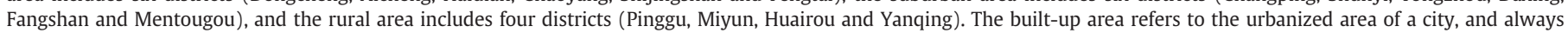
includes parts of the urban, suburban and rural areas (National Bureau of Statistics of China, 1990-2010). 
The results from this research provide insights into the relationship between urbanization and green space change, and provide a valuable reference for urban vegetation management and research.

\section{Materials and methods}

\subsection{Study sites}

According to the first urban directive 'Decision by the State Council regarding the establishment of cities and towns', issued in 1955 (PRC State Council, 1955), there exists a four-level urban system based on a specific administrative hierarchy: provincial-level municipalities directly under the jurisdiction of the central government ('Zhi_xia_shi'), prefecture-level cities ('Di_ji_shi'), county-level cities ('Xian_ji_shi') and towns ('Zhen') (Liu et al., 2003). In this paper we investigated 286 cities, including all the prefecture-level cities in all provinces of mainland China with the exception of Tibet, for which several years of socio-economic data were unavailable (Fig. 1). The four provinciallevel municipalities (Beijing, Shanghai, Tianjin and Chongqing) are commonly regarded as provinces in national statistical yearbooks, and in our discussion these cities are also treated as provinces in their own right (National Bureau of Statistics of China, 1990-2010).

The administrative boundary of cities in China often includes very large areas of countryside. In this study only the built-up area of each city was analyzed, rather than including the whole area within the administrative boundary. The built-up area refers to the urbanized area of a city, which always covers parts of the urban, suburban and rural area (National Bureau of Statistics of China, 1990-2010; Liu et al., 2003; see Fig. 2).

To investigate temporal trends in green space coverage, we divided cities into five groups based on green space coverage in 2009. In addition, in order to explore regional patterns in green space coverage, we divided the cities into six different regions (Northeast, North, Northwest, Southwest, Central-South and East), according to regional division criterion used by the national government. These six regions include all the provinces of mainland China.

\subsection{Data}

All the data for green space coverage and urbanization variables were compiled from the Statistics Yearbook of Cities in China (National Bureau of Statistics of China, 1990-2010). This series of yearbooks have been compiled and published annually by the National Bureau of Statistics since 1985. Providing basic data on the nationwide social-economicnatural situation, the yearbooks are widely used in city planning, assessment, management and research. Each yearbook published in a given year documents data from the previous year. We used the yearbooks published between 1990 and 2010 to collect data for the two decades between 1989 and 2009.

The concept of urbanization can vary from author to author (Weber and Puissant, 2003). In this paper, we use urbanization to refer to the complex process characterized by the transformation of landscapes formed by rural lifestyles into landscapes formed by urban ones (Antrop, 2000). Because urbanization is a process marked by urban area expansion with intensive land use change, economic development, and rapid population growth (Antrop, 2000; Weber and Puissant, 2003), we used all the continuously recorded variables related to population, land cover and economic development to analyze the influence of urbanization on green space coverage. These nine variables were defined or calculated according to the official statistical yearbooks (National Bureau of Statistics of China, 1990-2010; see Appendix A), and these definitions have remained unchanged during the last two decades.

Data for mean annual temperature and mean annual precipitation of each city were obtained from World-Clim (Hijmans et al., 2005) according to each city's geographical midpoint. The data of mean elevation was collected using the Digital Elevation Model (DEM) at $1 \mathrm{~km} \times 1 \mathrm{~km}$ resolution, obtained from the United States Geological Survey.

\subsection{Data analysis}

\subsubsection{Analysis of the temporal trend in green space coverage}

The temporal trend in green space coverage was studied using frequency distribution, temporal curves and trend values. The trend values for green space coverage of cities were calculated through least square linear regressions. The green space coverage in 2009 was used to examine the present situation, because it was the most recent available information.

\subsubsection{Analyses of the relationships between green space coverage and} urbanization variables

Examination of the distribution of the variables revealed that GDP, per capita GDP, urban land area, built-up area, percentage of built-up area, total population, population density, population in the builtup area, percentage of population in the built-up area, and mean elevation had a highly skewed distribution. As a result, these variables were ln-transformed before correlation and regression analysis was conducted.

The relationship between green space coverage and urbanization, climate and elevation variables was examined using simple regression analysis. As most investigated variables were significantly correlated with each other (see Appendix B), we conducted a series of multiple regression analyses in which green space coverage was the response variable and urbanization and environmental variables were predictors. We employed Akaike's information criterion (AIC) to select the best (lowest AIC) model.

To identify the individual variables that significantly affected the green space coverage, we applied hierarchical partitioning (using 'hier.part package' version 0.5-1, Walsh and Mac-Nally, 2003; Wang et al., 2011), implemented in R (http://www.r-project.org/). The hierarchical partitioning provides, for each explanatory variable separately, an estimate of the independent and joint contribution with all other variables (Heikkinen et al., 2005; Chevan and Sutherland, 1991; Mac-Nally, 2000; Quinn and Keough, 2002). To test the statistical significance of the independent contributions of variables, we also performed a randomization routine which yielded $Z$-scores for the generated distribution of randomized independent contributions, and a measure of statistical significance based on an upper 0.95 confidence limit (Mac-Nally, 2002; Heikkinen et al., 2005).

Spatial autocorrelation may lead to overestimated degree of freedom and thus can result in inflate Type I errors (Diniz-Filho et al., 2003). We examined the statistical significance of the correlations based on corrected degrees of freedom, and calculated by using Dutilleul's (1993) a modified $t$-test (Appendix B). A similar method was used to test the significance of the multiple regression model based on the corrected degree of freedom by correlating observed green space coverage and estimated green space coverage. In addition, to examine the spatial autocorrelations in green space coverage and its residuals of multiple regression model, we calculated Moran's I coefficient at various distances (Legendre, 1993). The statistical analysis and data processing in this study were all carried out using R statistical software 2.12.0 (R Development Core Team, 2011).

\section{Results}

\subsection{Recent situation of green space coverage and its historical trend}

The green space coverage within the built-up area in 2009 ranged from $2.8 \%$ to $69.8 \%$, with $59.7 \%$ of cities above the average value of $37.3 \%$. Of all the cities in mainland China, Shiyan in Hubei province had the highest green space coverage with $69.8 \%$, and Longnan in 

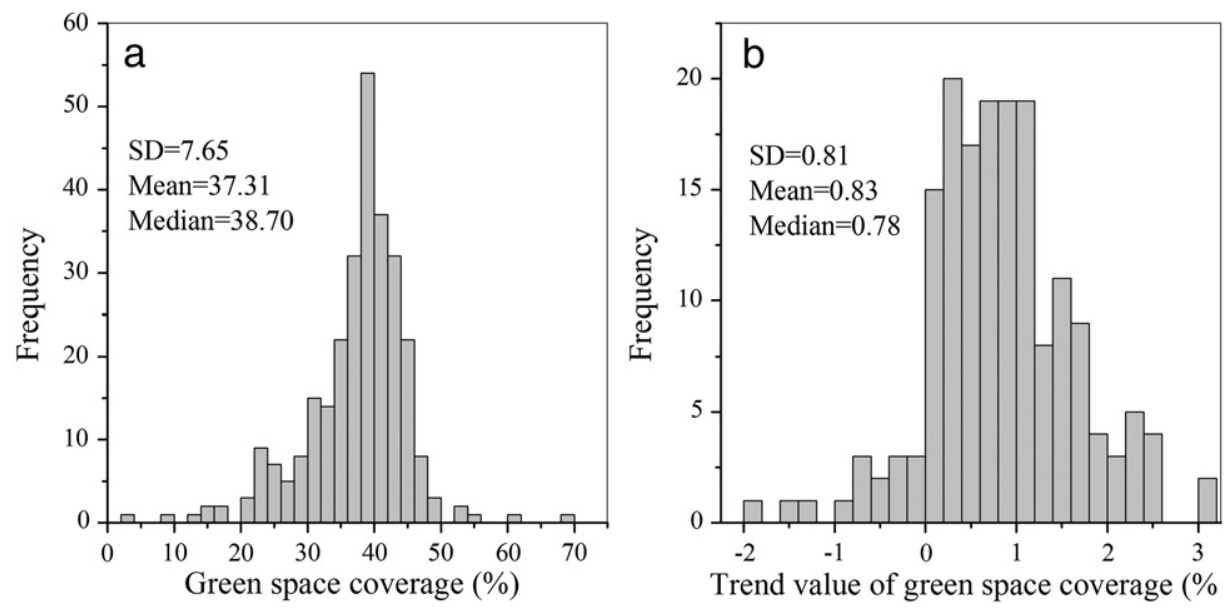

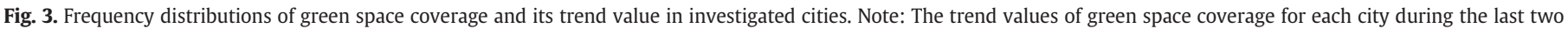
decades were estimated by the slopes from linear regressions.

Gansu province had the lowest coverage with only $2.8 \%$. However, green space coverage in most cities was between $35.0 \%$ and $45.0 \%$ (Fig. 3-a). The base requirement of green space coverage to establish a National Environmental Protection Model City of China is 35.0\%, and the base requirement to establish a National Ecological Garden City is $45.0 \% .73 .9 \%$ of the cities were above the Model City base level and $11.3 \%$ cities were above the Ecological Garden City level.

The green space coverage of most cities in China exhibited an increasing trend (Fig. 3-b). Of the cities investigated, 91.0\% had positive trend values, ranging from $0.0 \%$ to $3.2 \%$ (Fig. 3-b). $83.0 \%$ of the trend values were between $0.0 \%$ and $2.0 \%$, with the highest rate of increase occurring in Changzhi, Shanxi Province (3.2\%), and the highest negative trend in Benxi, Liaoning province $(-2.0 \%)$. Due to differences in standard deviation among cities, a definite threshold for significance of trend value did not appear. However, a trend value of $4.0 \%$ seems a possible turning point, because most trend values below $4.0 \%$ were insignificant while most of those above were significant.

\subsection{Characteristics of the temporal trend during the last two decades}

Improvement in green space coverage was obvious, since the average value increased steadily from $17.0 \%$ in 1989 to $37.3 \%$ in 2009 .
Moreover, an increasing percentage of cities had high green space coverage, while a decreasing percentage of cities had low green space coverage. Most cities were below $35.0 \%$ in 1989, but by 2009 a $73.9 \%$ of cities were above $45.0 \%$ (Fig. 4 -a). The number of cities with green space coverage between $35.1 \%$ and $45.0 \%$ increased from $3.2 \%$ of cities in 1989 to $62.2 \%$ of cities in 2009 (Fig. 4-a).

Further analysis showed that while increasing numbers of cities had higher green space coverage, city groups maintained their same ranking level relative to other city groups throughout the last two decades. For example, cities with highest level of green space coverage (over $45.0 \%$ ) in 2009 were assigned to group V. As shown in Fig. 4-b, this group maintained the highest level of average green space coverage throughout the entire study period, and similar results were also observed for the other groups.

\subsection{Comparison of the temporal trend among different provinces and regions}

Analysis of the average value of green space coverage in each region showed that cities in the Northeast region had the highest level of green space coverage, followed by the Central South region. The other four regions maintained the ranking of: Northeast region $>$ North region $>$ Southwest region $>$ Northwest region.
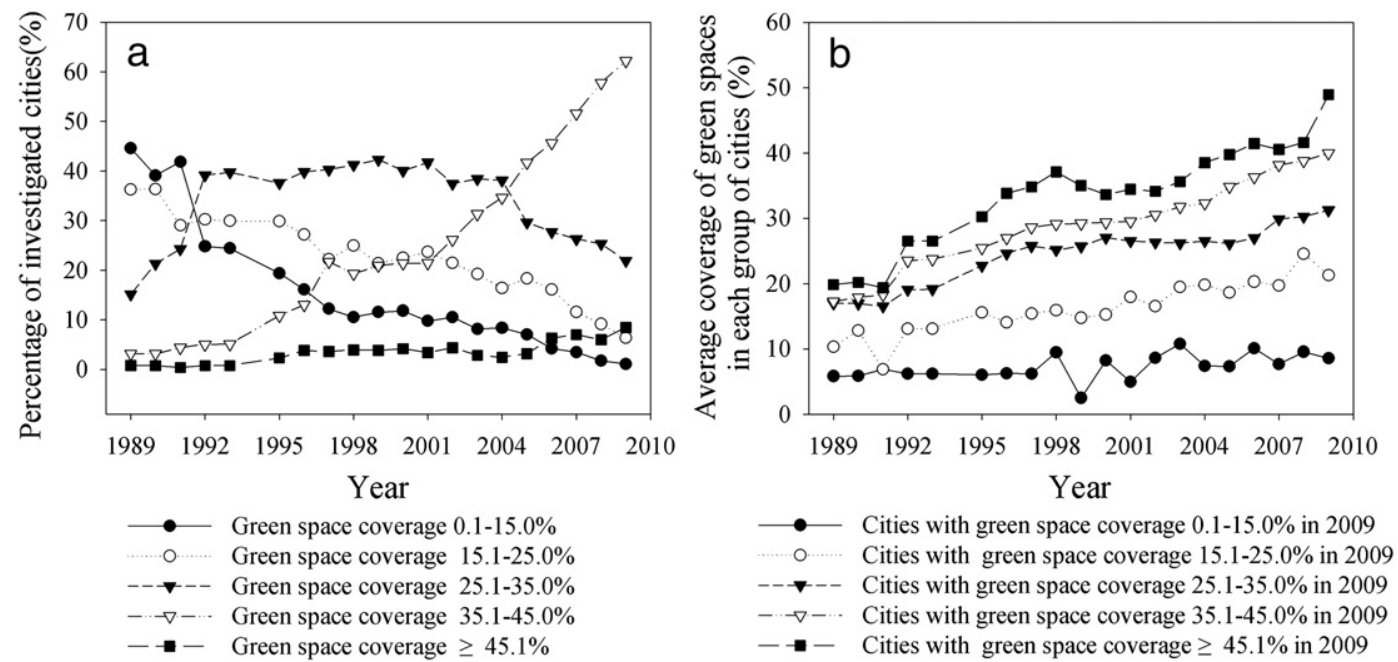

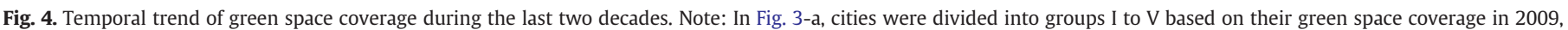
which is the latest year for which latest official data were available (National Bureau of Statistics of China, 1990-2010). 


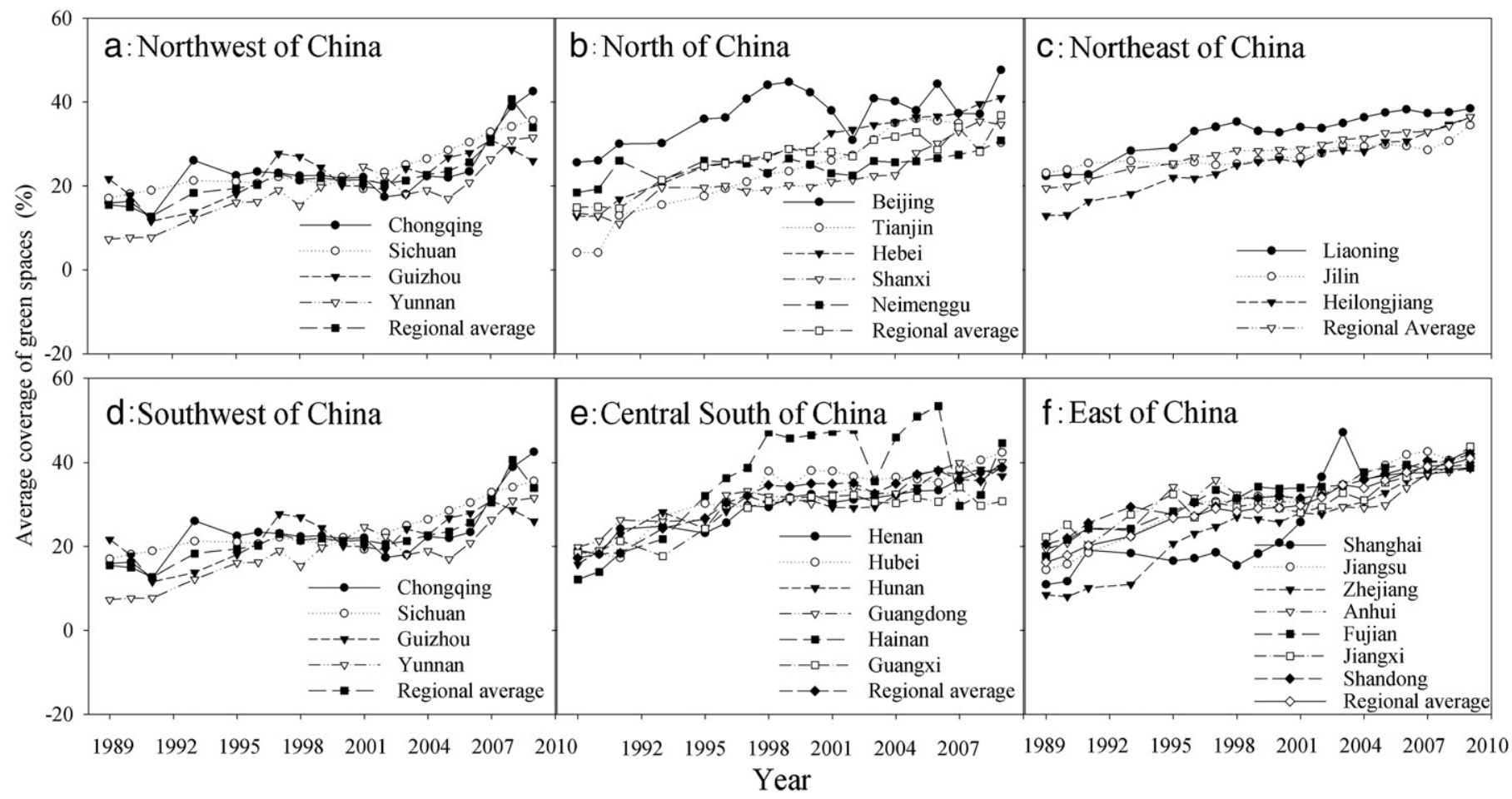

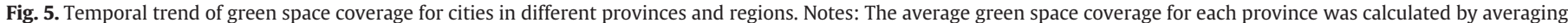

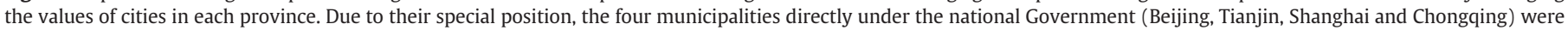
treated as provinces (Liu et al., 2003).

Provinces in the same region commonly had a similar level of green space coverage and largely similar development trend (Fig. 5). Most of the provinces in mainland China kept an increasing trend of green space coverage, with the exception of a few provinces which had a relatively complex development trend, for example Xinjiang and Ningxia provinces in the Northwest of China.

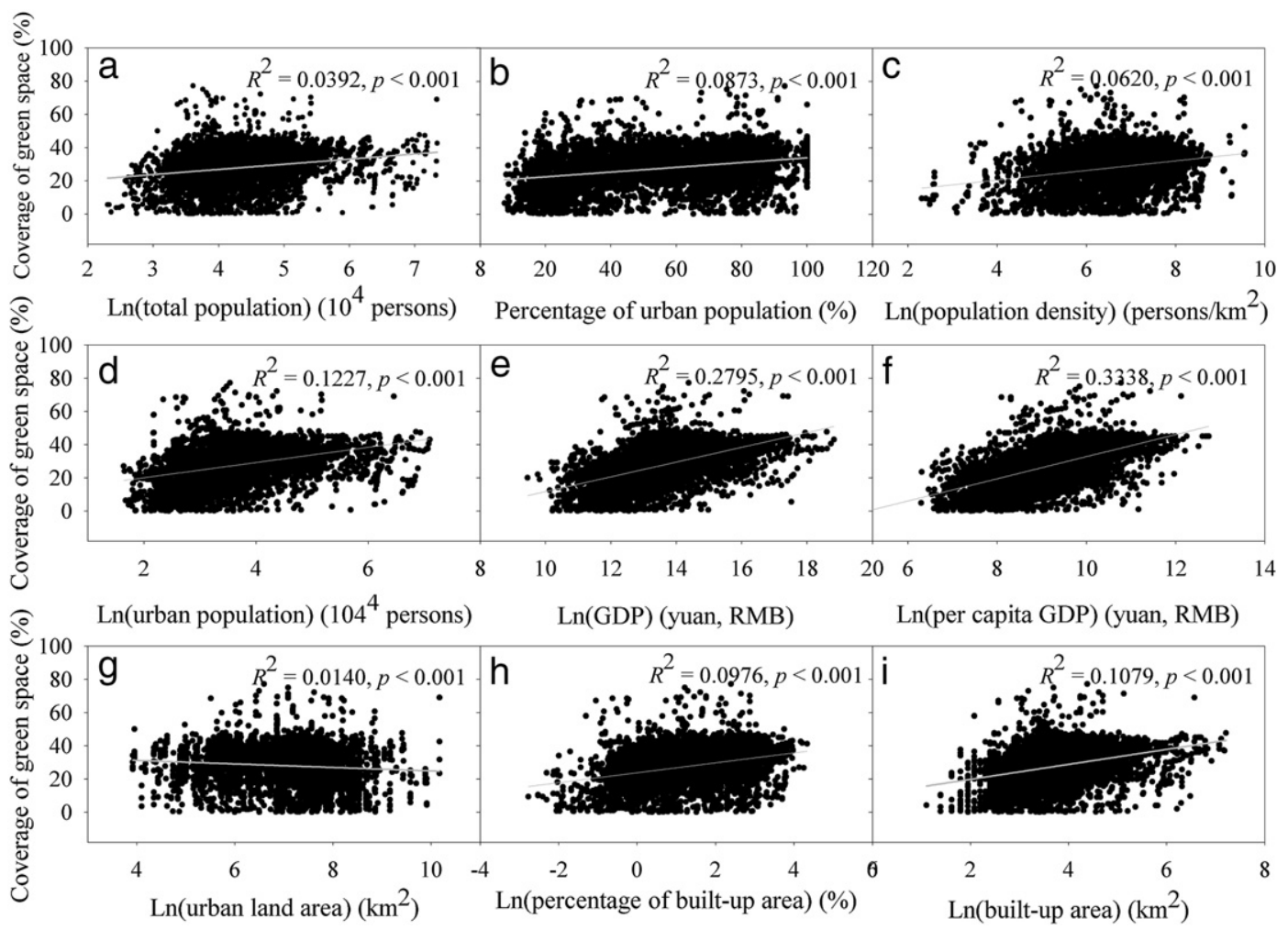

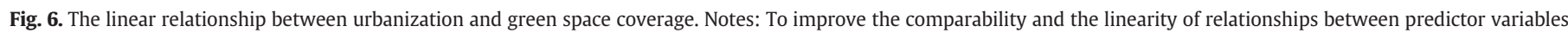
and trend of green space coverage, all the predictor variables were ln-transformed. 


\subsection{Relationship between predictor variables and green space coverage}

Eight of the nine urbanization variables had significant effects on green space coverage (Fig. 6), of which per capita GDP had the highest explanatory power (33\%). Urban land area and trend value of urban land area did not significantly influence the trend value of green space coverage, though trend value of built-up area did show a significant effect (Fig. 7, $R^{2}=0.0574, p<0.001$ ). Among the three climatic and elevation variables, only the mean elevation exhibited a significant influence on green space coverage (Fig. 8).

A model was constructed using the seven most significant variables as follows:

$$
\begin{aligned}
y= & -25.703+-0.44 b_{1}-0.094 b_{2}-2.756 b_{3}+9.473 b_{4}-0.654 b_{5} \\
& -6.5035 b_{6}+7.279 b_{7}
\end{aligned}
$$

where $y$ is the green space coverage and b1-7 are the variables shown in Table 1 . This model explained $48.7 \%$ of the variance of green space coverage.

At the finest scale of analysis, Moran's I did not show significant spatial autocorrelation in the residuals of green space coverage (Appendix C). This indicates the relatively low levels of unexplained deviance in green space coverage left by this multi regression model.

\subsection{Relative effects of individual variables}

After linear regression for all individual urbanization variables, the seven most significant variables were selected to perform a hierarchical partitioning. Among the seven most significant variables, 'per capita GDP' exhibited the highest independent contribution, followed by 'population in the built-up area' and 'built-up area', respectively contributing $24.2 \%, 4.2 \%$ and $4.0 \%$ (Fig. 9 ).

\section{Discussion}

As shown above, green space coverage in cities in China has been increasing rapidly during the last two decades and the influence of urbanization or urban sprawl was demonstrated to be significant. Unlike in natural forests, green spaces in built-up areas are mostly artificial and intensively cultivated (Zhao et al., 2010). As demonstrated by this study, the influence of climate or geographic factors is rather limited. During the process of urban sprawl, land in the wider countryside is gradually occupied, and new green space is constructed artificially (e.g. Antrop, 2000; Swenson and Franklin, 2000; Dallimer et al., 2011). Where and how urban green space is distributed is commonly controlled entirely by humans, which means that socio-economic factors significantly influence green space coverage in built-up areas. To demonstrate the effect mechanisms of green space coverage, investigation into the processes of urban sprawl and the effects of socio-economic factors may be an important first step.

The finding that green space coverage in China's built-up areas experienced a steady increase in the last two decades is completely opposite to that of some other reports, which stated that rapid urbanization had led to a reduction in green space (McDonald et al., 2010; Pauleit et al., 2005). This contradiction may be partly due to different patterns of urban expansion in developed and developing countries. In China, most cities developed through expansion into surrounding countryside, but within the built-up area itself, green space construction has been encouraged, supported and managed by the national government. During the last two decades, many new green spaces have been constructed, especially in cities which have reached a higher

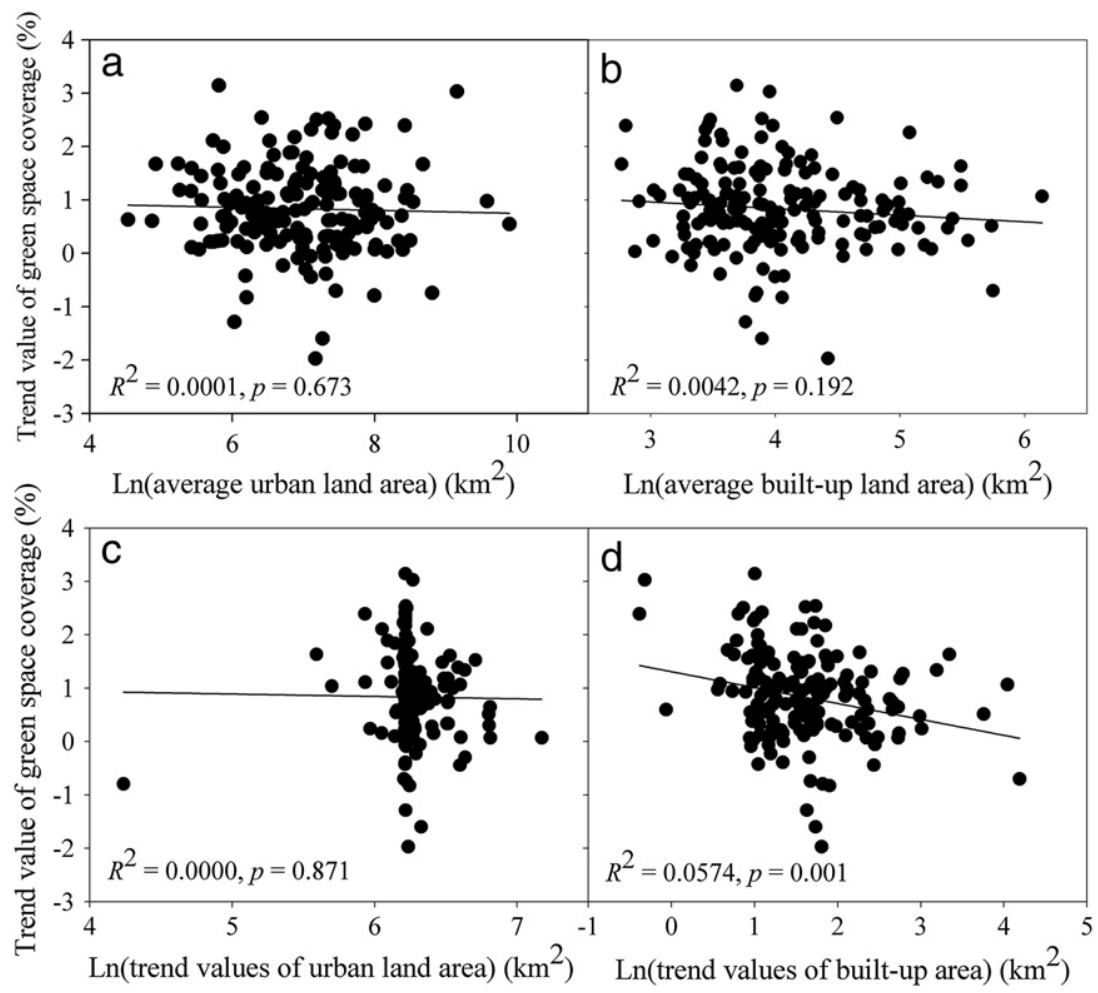

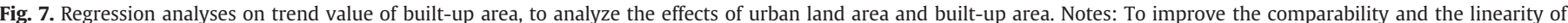

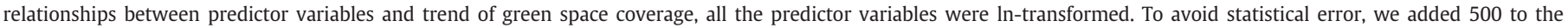

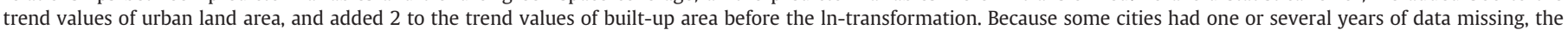
trend value was not available for all cities investigated. 

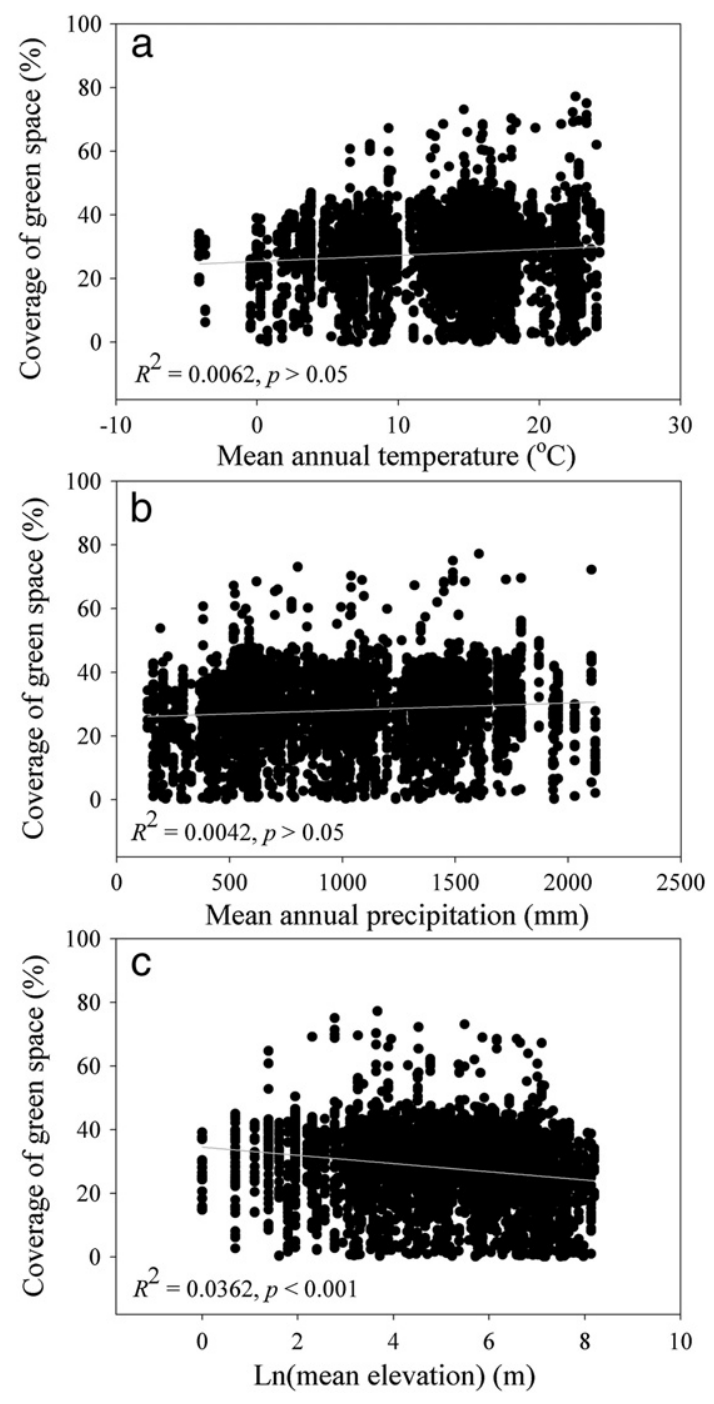

Fig. 8. The relationship between green space coverage and climate and elevation variables. Notes: Due to a highly skewed distribution, the predictor mean elevation was ln-transformed.

level of economic development. In contrast, the reduction found in the two studies referenced above was demonstrated to be caused by reuse and occupation of green space and population growth, and infill development whereby gardens were built over was a significant

Table 1

Summary of the multiple regression models, in which coverage of green space is the response variable, and mean elevation and urbanization variables are predictors.

\begin{tabular}{llrllll}
\hline Variable & $\begin{array}{l}\text { Label for } \\
\text { variables }\end{array}$ & Coefficient & $\begin{array}{l}\text { Std } \\
\text { coefficient }\end{array}$ & $\begin{array}{l}\text { Std } \\
\text { error }\end{array}$ & $t$ & $p$ \\
\hline Constant & & -25.703 & 0.000 & 2.684 & -9.578 & $<0.001$ \\
ME & $\mathrm{b}_{1}$ & -0.440 & -0.065 & 0.082 & -5.371 & $<0.001$ \\
PPBA & $\mathrm{b}_{2}$ & -0.094 & -0.194 & 0.023 & -4.135 & $<0.001$ \\
TP & $\mathrm{b}_{3}$ & -2.756 & -0.176 & 1.067 & -2.582 & $<0.001$ \\
PBA & $\mathrm{b}_{4}$ & +9.473 & +0.724 & 1.117 & +8.480 & $<0.001$ \\
ULA & $\mathrm{b}_{5}$ & -0.654 & -0.059 & 0.167 & -3.918 & $<0.001$ \\
BUA & $\mathrm{b}_{6}$ & -6.503 & -0.473 & 0.416 & -15.644 & $<0.001$ \\
PCGDP & $\mathrm{b}_{7}$ & +7.279 & +0.631 & 0.176 & +41.460 & $<0.001$ \\
\hline
\end{tabular}

Notes: ME is 'mean elevation', PPBA is ‘percentage of population in the built-up area', TP is 'total population', PBA is 'population in the built-up area', ULA is 'urban land area', BUA is 'built-up area', and PCGDP is 'per capita GDP'.

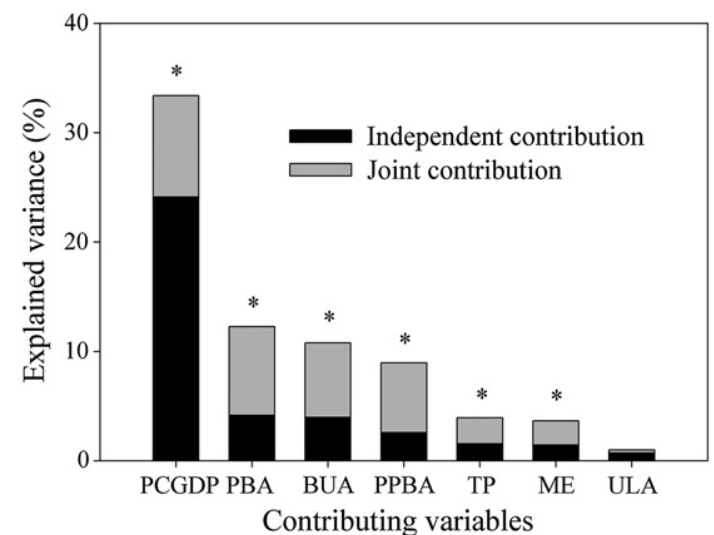

Fig. 9. Contributions to the variance of green space coverage by the seven most significant variables. Notes: '*' denotes the effect due to this variable and is significant at $p<0.05$. All the predictor variables were ln-transformed. PCGDP is 'per capita GDP', PBA is 'population in the built-up area', BUA is 'built-up area', PPBA is 'percentage of population in the built-up area', TP is 'total population', ME is 'mean elevation', and ULA is 'urban land area'.

contributing factor (Pauleit et al., 2005). Urbanization changes land-use patterns, resulting in the occupation of green space (Kong and Nakagoshi, 2006), and the amount of open space loss is strongly correlated with changes in population, with cities with a greater increase in population losing more open space (McDonald et al., 2010). However, no matter whether cities 'sprawl' into the wider countryside or 'densify' through the development of existing urban green space, some green space is always occupied. Achieving quality green space in the built-up area may therefore demand other more constructive way of urban expansion.

We found obvious regional differences in green space coverage. Most cities or provinces in the Central South and the East maintained high levels of green space coverage, but those in other regions were mostly near or below the national average, similar to earlier findings (Sun et al., 2011). This type of regional difference may result from geographic, climate and economic factors. City development in the west of China was not accelerated until the national Government's policy emphasizing regional balance in economic development (Zhou and Cao, 1999), resulting in limited economic support for urban greening. In addition, compared to the central areas of China, the west of China is much dryer and lower in plant productivity, with annual precipitation less than $400 \mathrm{~mm}$ and arid or semi-arid vegetation dominates (Sun et al., 2011). However, we found that green space development could still occur at different rates in cities in the same region.

Cities with lower levels of green space coverage may encounter extraordinary difficulties in increasing green space, because current greening conditions largely indicate the future development of green space coverage. As demonstrated by this research, cities with lower green space coverage in 2009 also had lower green space coverage throughout the last two decades. To achieve an improvement in green space, disadvantaged cities would likely need to exert much more effort than advantaged cities. However, cities with lower green space coverage are mostly located in the north and west regions where climate and geographic conditions are relatively unfavorable, and the economic development level is also relatively low. When government agencies or researchers try to assess and compare the development of green space in Chinese cities, it is important to consider historical conditions and development limitations, because these conditions mean that the same amount of effort may achieve very different results.

The improvement of green space coverage in the built-up area of cities in China may be partly attributed to ongoing urbanization (Zhao et al., 2012). As demonstrated by this research, the nine 
indicators of urbanization all have a positive effect on green space coverage in the built-up area, though urbanization may have generally reduced the greenness of China as a whole (Masek et al., 2000; Sun et al., 2011; Zhou and Wang, 2011). Of the six most significant urbanization variables, per capita GDP was found to have the largest independent contribution to the variance of green space coverage. It seems that higher income levels have resulted in widespread urban forest construction in the built-up areas of richer cities. In fact, urban forest development has occurred rapidly in cities with a high economic level, and great achievements have already been made (Zhang, 1997). For example, while coastal cities have a higher urbanization rate than that of the national average (Shen, 2005), we found that urban green space coverage in this region was the highest in China. Conversely, the economic level of cities in the west of China is relatively low, and urban green space coverage is also relatively low. Because urbanization is commonly accompanied by an improvement in economic conditions, more urbanized cities could likely accomplish better greening by rational planning and management (Jiang, 2011).

However, the rapid development of green space coverage would not be possible without the supporting policies of the national Government. As reported earlier, while social factors are the primary influence on urban greening ( $\mathrm{Li}, 2001)$, policies have also been reported to contribute to the increase in urban green space area (Kong and Nakagoshi, 2006; Zhou and Wang, 2011). In China, the Regulations of Urban Greening was promulgated by the State Council in 1992 to guide the planning, management, protection, and construction of urban green spaces. In addition, to encourage urban greening, the Ministry of Housing and Urban-rural Development of China issued the Standards of National Garden City in 2000 and improved these standards in 2005 and 2010.

These policies have significant effects. For example, because the base requirement of green space coverage to apply for the National Garden City award is 35\%, many cities made this amount of green space coverage an important target in local planning. As a result, the percentage of cities with green space coverage above $35 \%$ increased rapidly during the last two decades, as demonstrated by this study. However, there have been few empirical evaluations of the impacts of specific land development policies on urban land cover (e.g., Stone and Norman, 2006; Wilson et al., 2003) or urban tree cover (e.g., Conway and Urbani, 2007; Heynen and Lindsey, 2003; McPherson, 2001; Wilson et al., 2003). Although ecological processes can be integrated with social and economic factors through computer modeling and simulation (Liu, 2001), evaluating the impact of specific land development regulations on urban tree cover remains an important gap in the literature (Landry and $\mathrm{Pu}, 2010$ ).

\section{Conclusion}

In conclusion, urban green space coverage in the built-up area of Chinese cities has increased steadily during the last two decades. Most cities in each region were found to have similar long-term levels of green space coverage and development trends were also largely similar. We found that groups of cities with different levels of recent green space coverage also maintained their relative level of green space coverage throughout the last two decades, compared to other groups of cities. Urbanization was demonstrated to positively contribute to green space coverage, and the relationship significantly fit the linear function. Eight of the nine variables characterizing urbanization showed significant positive linear relationships with green space coverage, with 'per capita GDP' having the highest independent contribution (24.2\%). However, among the climatic and geographic factors investigated, only the mean elevation showed significant influence. Finally, green space coverage in built-up areas tended to reflect the effects of urbanization rather than climatic or geographic factors. To study the effect mechanisms of green space coverage, investigation into the processes of urban sprawl and the effects of socio-economic factors may be a vital first step.

\section{Acknowledgments}

This work was jointly supported by the National Science Foundation of China (31200363 and 31270588), CAS/SAFEA International Partnership Program for Creative Research Teams (KZCX2-YWT08), Knowledge Innovation Project of the CAS (KZCX-2-YW-453 and Y2L0331D60), National Forestry Public Welfare Foundation of China (201304205 and 201204604), Fujian Provincial Department of Science and Technology (2009J01189 and 2011Y0052), Xiamen Municipal Department of Science and Technology (3502Z20092005 and 3502Z20101015) and the national funding for "Remote Sensing Survey and Assessment of National Eco-environmental Changes in the Past Decade (2000-2010)" (STSN-11-02). Many thanks are due to Dr. Xiaoma Li, Dr. Yunjian Luo and Dr. Quanyi Qiu (Chinese Academy of Sciences) for their dedicated help.

\section{Appendix A. Concepts and definitions}

(1) Green space coverage: Green space coverage is the coverage of green space in the built-up area of a city, and is calculated by dividing the green space area by the total built-up area. Green space coverage is the vertical projection area of the trees, shrubs and herbs planted for urban greening within a built-up area, including park green space, protection green space, institutional green space, road green space, etc. Areas where shrubs and herbs are planted beneath an overhanging tree canopy should not be double counted. Although domestic gardens make an important contribution to the green space infrastructure in Europe (Davies et al., 2009), in China they are rare and commonly forbidden in built-up areas by the national government. As a result, green space coverage is mainly composed of public green space, and do not include domestic or private gardens.

(2) GDP: Gross Domestic Product (GDP) in this paper refers to the final products at market prices produced by all resident units in a city in a given year.

(3) Per capita GDP: Per capita GDP is calculated by dividing total GDP by total population of a city.

(4) Urban land area: Urban land area is the land area within the urban region of a city, as distinguished from suburban and rural areas (Fig. 1).

(5) Built-up area: In China, built-up area refers to the urbanized area of a city and always includes parts of the urban, rural and suburban areas. Built-up areas are planned and constructed by the government and provided with substantial municipal infrastructure (Fig. 1).

(6) Percentage of built-up area: Percentage of built-up area is the ratio of built-up area within a city, and is calculated by dividing the built-up area by the area within the administrative boundary of a city.

(7) Total population: Total population refers to the total number of people within the administrative boundary of a given city at midnight on the 3lst of December in a given year.

(8) Population density: Population density is the total population divided by the land area of a city.

(9) Population in the built-up area: Population in the built-up area refers to the number of people residing within the built-up area.

(10) Percentage of population in the built-up area: Percentage of population in the built-up area is calculated by dividing population in the built-up area by total population.

(11) Mean elevation: Mean elevation in this paper refers to the mean elevation of the built-up area. Because the built-up area is usually concentrated around the city center, the elevation in the center of the downtown area was adopted as the mean elevation. 
Appendix B. Correlation between urbanization and environmental variables

\begin{tabular}{|c|c|c|c|c|c|c|c|c|c|c|c|}
\hline & GDP & PCGDP & ULA & BUA & PBUA & $\mathrm{TP}$ & PD & PBA & РPBA & $\mathrm{ME}$ & AAT \\
\hline PCGDP & $0.85^{*}$ & & & & & & & & & & \\
\hline ULA & $0.20^{*}$ & 0.03 & & & & & & & & & \\
\hline BUA & $0.83^{*}$ & $0.59^{*}$ & 0.19* & & & & & & & & \\
\hline PBUA & $0.40^{*}$ & $0.43^{*}$ & $-0.73^{*}$ & $0.53^{*}$ & & & & & & & \\
\hline $\mathrm{TP}$ & $0.70^{*}$ & $0.22^{*}$ & $0.41^{*}$ & $0.74^{*}$ & $0.15^{*}$ & & & & & & \\
\hline PD & $0.30^{*}$ & $0.19 *$ & $-0.74^{*}$ & $0.34^{*}$ & $0.87^{*}$ & $0.30^{*}$ & & & & & \\
\hline PBA & $0.78^{*}$ & $0.47^{*}$ & $0.10^{*}$ & $0.90^{*}$ & $0.54^{*}$ & $0.81^{*}$ & $0.49^{*}$ & & & & \\
\hline PPBA & $0.33^{*}$ & $0.46^{*}$ & $-0.41^{*}$ & $0.49 *$ & $0.70^{*}$ & 0.00 & $0.42^{*}$ & $0.56^{*}$ & & & \\
\hline ME & $-0.19^{*}$ & $-0.15^{*}$ & $0.24^{*}$ & $-0.14^{*}$ & $-0.31^{*}$ & $-0.13^{*}$ & $-0.35^{*}$ & $-0.17^{*}$ & $-0.17^{*}$ & & \\
\hline AAT & 0.03 & 0.03 & $-0.18^{*}$ & $-0.13^{*}$ & $0.06^{*}$ & 0.03 & $0.21^{*}$ & $0.10^{*}$ & $-0.10^{*}$ & $-0.39^{*}$ & \\
\hline $\mathrm{AP}$ & 0.00 & 0.00 & $-0.08^{*}$ & $-0.10^{*}$ & 0.00 & 0.00 & $0.09^{*}$ & $0.08^{*}$ & $0.08^{*}$ & $-0.23^{*}$ & $0.79^{*}$ \\
\hline
\end{tabular}

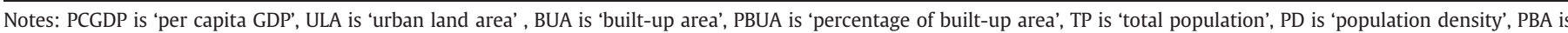

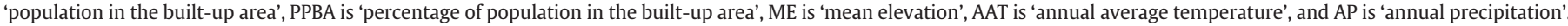

'*' indicates that the effect due to this variable is significant at $p<0.05$.

\section{Appendix C. A test on spatial correlation, by the trend of Moran's I with variation of spatial distance}

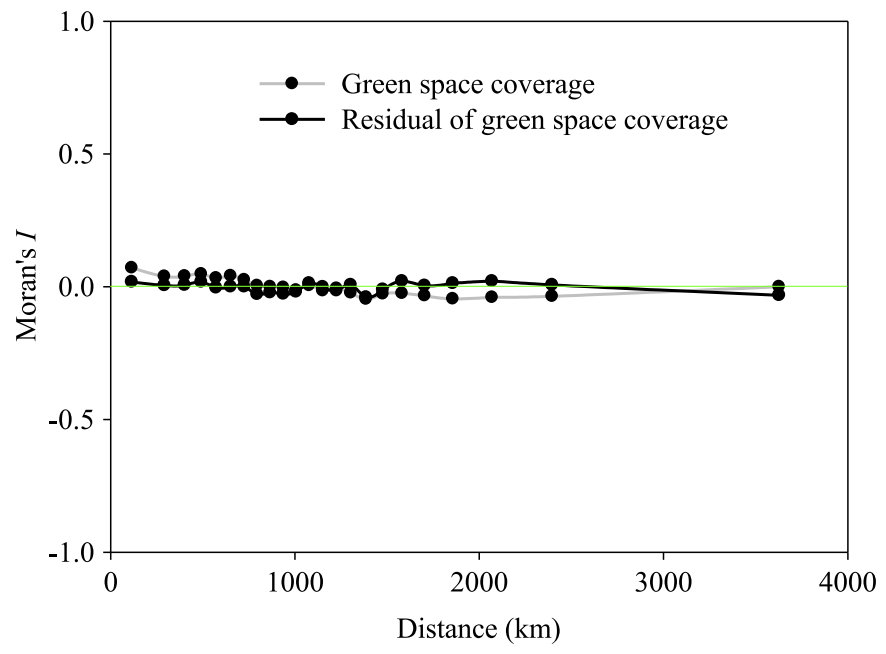

Notes: We conducted this test because spatial autocorrelation may lead to overestimate degree of freedom and thus can result in inflate Type I errors (Diniz-Filho et al., 2003). As shown in this figure, the spatial autocorrelation of green space coverage is relatively low.

\section{References}

Antrop M. Changing patterns in the urbanized countryside of Western Europe. Landsc Ecol 2000;15:257-70.

Beer AR, Delshammar T, Schildwacht P. A changing understanding of the role of greenspace in high-density housing-a European perspective. Build Environ 2003;29(2):132-43

Chen WY, Jim CY. Assess and valuation of the ecosystem services provided by urban forests. In: Carreiro MM, Song YC, Wu J, editors. Ecology, planning, and management of urban forests international perspectives. New York: Springer; 2008. p. 53-83.

Chevan A, Sutherland M. Hierarchical partitioning. Am Stat 1991;45(2):90-6.

Churkina G, Brown DG, Keoleian G. Carbon stored in human settlements: the conterminous United States. Glob Chang Biol 2010;16:135-43.

Conway TM, Urbani L. Variations in municipal urban forestry policies: a case study of Toronto, Canada. Urban For Urban Green 2007;6(3):181-92.

Crane P, Kinzig A. Nature in the metropolis. Science 2005;308:1225.

Dallimer M, Tang Z, Bibby PR, Brindley P, Gaston KJ, Davies ZG. Temporal changes in greenspace in a highly urbanized region. Biol Lett 2011;7:763-6.

Davies ZG, Fuller RA, Loram A, Irvine KN, Sims V, Gaston KJ. A national scale inventory of resource provision for biodiversity within domestic gardens. Biol Conserv 2009;142:761-71.
Davies ZG, Edmondson JL, Heinemeyer A, Leake JR, Gaston KJ. Mapping an urban ecosystem service: quantifying above-ground carbon storage at a city-wide scale. J Appl Ecol 2011;48:1125-34.

Diniz-Filho JAF, Bini LM, Hawkins BA. Spatial autocorrelation and red herrings in geographical ecology. Global Ecol Biogeogr 2003;12:53-64.

Dutilleul P. Modifying the t test for assessing the correlation between two spatial processes. Biometrics 1993;49:305-14.

Fang WB. Quantify the ecological system and the construction of urban green space-a national scientific and technological innovation in Hefei city, the pilot demonstration area green land planning as an example. Wuhan (Hubei): Huazhong University of Science and Technology; 2008 [Chinese].

Fang JY, Piao SL, Field CB, Pan YD, Guo OH, Zhou LM, et al. Increasing net primary production in China from 1982 to 1999. Front Ecol Environ 2003;1:293-7.

Fuller RA, Gaston KJ. The scaling of green space coverage in European cities. Biol Lett 2009;5:352-5.

Grimm NB, Faeth SH, Golubiewski NE, Redman CL, Wu JG, Bai XM, et al. Global change and the ecology of cities. Science 2008;319:756-60.

Heikkinen RK, Luoto M, Kuussaari M, Pöyry J. New insights into butterfly-environment relationships using partitioning methods. Proc R Soc Lond B Biol Sci 2005;272(1577): 2203.

Heynen NC, Lindsey G. Correlates of urban forest canopy cover - implications for loca public works. Public Work Manag Policy 2003;8:33-47.

Hijmans RJ, Cameron SE, Parra JL, Parra JL, Jones PG, Jarvis A. Very high resolution interpolated climate surfaces for global land areas. Int J Climatol 2005;25:1965-78.

Jiang SD. The bottlenecks of in the development of urban gardening and greening in China at present. Technol Landsc Archit 2011;3:8-13. [Chinese].

Jim CY, Chen S. Comprehensive green space planning based on landscape ecology principles in compact Nanjing city, China. Landsc Urban Plan 2003;65:95-116.

Jo HK. Impacts of urban green space on offsetting carbon emissions for middle Korea. J Environ Manage 2002;64:115-26.

Kirkpatrick JB, Daniels GD, Davison A. Temporal and spatial variation in garden and street trees in six eastern Australian cities. Landsc Urban Plan 2011;101:244-52.

Kong FH, Nakagoshi N. Spatial-temporal gradient analysis of urban green spaces in Jinan, China. Landsc Urban Plan 2006;78:147-64.

Landry S, Pu RL. The impact of land development regulation on residential tree cover: an empirical evaluation using high-resolution IKONOS imagery. Landsc Urban Plan 2010:94:94-104.

Legendre P. Spatial autocorrelation: trouble or new paradigm? Ecology 1993;74:1659-73.

Li F. The research of evaluating index system and type classification of urban forest in West China. Beijing: Chinese Academy of Forestry; 2001 [Chinese].

Liu JG. Integrating ecology with human demography, behavior, and socioeconomics: needs and approaches. Ecol Model 2001;140:1-8.

Liu S, Li X, Zhang M. Institute of Geographic Sciences and Natural resources Research, Chinese Academy of Sciences, Beijing, China. Scenario Analysis on urbanization and Rural-urban Migration in China. Interim ReportLaxenburg, Austria: International Institute for Applied Systems Analysis; 2003.. Aug. Report No.: A-2361.

Liu G, Yang Z, Chen B, Ulgiati S. Monitoring trends of urban development and environmental impact of Beijing, 1999-2006. Sci Total Environ 2011;409(18):3295-308.

Mac-Nally R. Regression and model-building in conservation biology, biogeography and ecology: the distinction between - and reconciliation of - 'predictive' and ‘explanatory’ models. Biodivers Conserv 2000;9:655-71.

Mac-Nally R. Multiple regression and inference in ecology and conservation biology: further comments on identifying important predictor variables. Biodivers Conserv 2002;11(8):1397-401.

Masek JG, Lindsay FE, Goward SN. Dynamics of urban growth in the Washington DC metropolitan area, 1973-1996, from Landsat observations. Int J Remote Sens 2000;21: 3473-86.

McDonald RI, Forman RTT, Kareiva P. Open space loss and land inequality in United States' cities, 1990-2000. PLoS One 2010;5(3):e9509. 
McPherson EG. Sacramento's parking lot shading ordinance: environmental and economic costs of compliance. Landsc Urban Plan 2001;57(2):105-23.

National Bureau of Statistics of China. China City Statistical Yearbook. Beijing: China Statistics Press; 1990-2010 [Chinese].

Pauleit S, Ennos R, Golding Y. Modeling the environmental impacts of urban land use and land cover change-a study in Merseyside, UK. Landsc Urban Plan 2005;71:295-310.

PRC State Council. Decision by the State Council regarding the establishment of cities and towns. Beijing: PRC State Council; 1955

Quinn GP, Keough MJ. Experimental Design and Data Analysis for Biologists. Cambridge: Cambridge University Press; 2002.

$\mathrm{R}$ Development Core Team. A language and environment for statistical computing Vienna, Austria: R Foundation for Statistical Computing3-900051-07-0; 2011. http://www.R-project.org.

Ren Y, Wei X, Wei XH, Pan JZ, Xie PP, Song XD, et al. Relationship between vegetation carbon storage and urbanization: a case study of Xiamen, China. For Ecol Manage 2011;261:1214-23.

Ridder K De, Adamec V, Bañuelos A, Bruse M, Bürger M, Damsgaard O, et al. An integrated methodology to assess the benefits of urban green space. Sci Total Environ 2004;334/335:489-97.

Shen JF. Analysis of the trends of urbanization levels in Chinese Provinces since 1982. Acta Geogr Sin 2005;60:607-14. Chinese.

Stone B, Norman JM. Land use planning and surface heat island formation: a parcelbased radiation flux approach. Atmos Environ 2006;40(19):3561-73.

Sun JY, Wang XH, Chen AP, Ma YC, Cui MD, Piao SL. NDVI indicated characteristics of vegetation cover change in China's metropolises over the last three decades. Environ Monit Assess 2011;179:1-14.
Swenson JJ, Franklin J. The effects of future urban development on habitat fragmentation in the Santa Monica Mountains. Landsc Ecol 2000;15:713-30.

Walsh CJ, Mac-Nally R. Hierarchical Partitioning. R Project for Statistical Computing; 2003. http://cran.r-project.org/.

Wang JY. Review and prospect of greening and gardening construction in China. Chin Landsc Archit 1992;8:17-25. [Chinese].

Wang H, Ouyang Z, Chen W, Wang X, Zheng H, Ren Y. Water, heat, and airborne pollutants effects on transpiration of urban trees. Environ Pollut 2011:159(8-9):2127-37.

Weber C, Puissant A. Urbanization pressure and modeling of urban growth: example of the Tunis Metropolitan Area. Remote Sens Environ 2003;86:341-52.

Wilson JS, Clay M, Martin E, Stuckey D, Vedder-Risch K. Evaluating environmental influences of zoning in urban ecosystems with remote sensing. Remote Sens Environ 2003;86(3):303-21.

Zhang H. Green city is more green. Chin For 1997;7:18-9. [Chinese].

Zhao JJ, Ouyang ZY, Zheng H, Zhou WQ Wang XK, Xu WH, et al. Plant species composition in green spaces within the built-up of Beijing, China. Plant Ecol 2010;209(2): 189-204.

Zhao JJ, Chen SB, Wang H, Ren Y, Du K, Xu WH, et al. Quantifying the impacts of socio-economic factors on air quality in Chinese cities from 2000 to 2009. Environ Pollut 2012;167:148-54.

Zhou YX, Cao GZ. The urbanization process of China since 1978. City Plann Rev 1999;23:8-12.

Zhou XL, Wang YC. Spatial-temporal dynamics of urban green space in response to rapid urbanization and greening policies. Landsc Urban Plan 2011;100:268-77. 